\title{
O que pensam os formadores dos futuros professores sobre ser professor e formar professores
}

\author{
Sílvia Adriana Rodrigues* \\ Simone Conceição Pereira Deák*** \\ Alberto Albuquerque Gomes ${ }^{* * *}$
}

\begin{abstract}
Resumo
A presente discussão é recorte de uma pesquisa longitudinal, em andamento desde 2011, com objetivo geral de acompanhar processos de formação inicial para a docência, em distintas instituições públicas de ensino superior, com vistas à compreensão de como se dá a evolução da aprendizagem profissional, tendo como sujeitos alunos e professores de cursos de Pedagogia, de universidades localizadas em duas regiões brasileiras distintas. Assim, nos limites deste texto, com a intenção de discutir a imagem que os professores dos cursos de formação inicial detêm sobre o que é ser professor e o que é ser formador de professores, são apresentados dados obtidos no ano de 2012, junto a 33 sujeitos, professores de duas universidades públicas. A análise dos dados nos permite inferir que o processo de formação dos formadores de professores é de autoformação e de um saber construído sobre a experiência, na situação de autodidatismo em potencial e em aceleração.

Palavras-chave: Formação inicial de professores; Formadores de professores; Ensino Superior.
\end{abstract}

\section{What trainers of future teachers think about being teacher and training teachers}

\begin{abstract} and accelerated.

Não me preparei para ser um universitário, mas fui universitário no sentido pleno da palavra. A tal ponto que quando deixei de ser universitário, fiquei desarvorado. Eu não sei pra onde vou. Estou numa crise que é psicológica, é moral e é política... (pois)... perdi um ponto de referência e de identidade que poderia ser muito vantajoso. para minha sobrevivência e o meu trabalho (FERNANDES, 1975). ${ }^{2}$
\end{abstract}

This discussion is part of a longitudinal study, ongoing since 2011, with the overall objective to follow up the processes of initial training for teaching in different public institutions of higher education, aiming to understanding how it is the development of professional learning. The participants were students and teachers of pedagogy courses within universities located in two distinct Brazilian areas. Thus, considering the limits of this paper, with the intention of discussing the representation of what teachers of initial training courses have about what means to be a teacher and what represents to be a teacher trainer for them, data obtained in 2012 are presented, along with 33 subjects, teachers from two public universities. The findings made us to conclude that the process of teacher training is self-training, and knowledge built on experience field, in a situation of self-learning potential

Keywords: Initial teacher training; Teacher trainers; Higher Education.

\section{Introdução}

A vertiginosa expansão de oportunidades escolares, verificada nos anos 1980 e 1990, além de proporcionar o acesso em massa da população em idade escolar, propiciou a ampliação do Ensino Fundamental para 9 anos, incluindo obrigatoriamente crianças de seis anos (Leis $\mathrm{n}^{\circ}$. $11.114 / 2005$ e $11.274 / 2006$ ).

Nesse contexto, a questão da formação inicial de professores para a educação básica, com vistas a atender a essa demanda, tornou-se, neste início de século, prioridade absoluta na educação brasileira, de modo que o país tem sido pródigo na formulação de diplomas legais, os quais disciplinem a formação inicial de professores (LDB 9.394/96; Parecer CNE/CP 09/2001; Resolução CNE/CP 01/2002 e Resolução CNE/CP 01/2006).

Paralelamente, observa-se um contexto marcado por uma expressiva modernização econômica e crescente respeito aos direitos de cidadania, que tem pressionado os sistemas de ensino público a deflagrar processos de reformas educacionais as quais afetam diretamente as políticas de formação inicial de professores.

\footnotetext{
*Endereço eletrônico: silvia.rodrigues@ufms.br

***Endereço eletrônico: sideak@gmail.com

*** Endereço eletrônico: alberto@ fct.unesp.br
} 
Partimos então do pressuposto de que a formação inicial é somente uma faceta do complexo processo de preparação de quadros profissionais para a educação básica, considerando-se a questão tanto de forma quantitativa quanto qualitativa.

Nessa direção, embora seja um tema relevante no cenário da formação inicial de professores, ousamos afirmar que ainda são tímidas, ou mesmo insuficientes, as discussões e a produção de conhecimentos sobre os formadores de professores que atuam no Ensino Superior, sua formação, identidade, concepções etc. Embora a discussão envolvendo esse nível de ensino tenha começado a fazer parte do debate, de forma mais sistemática, e ganhado visibilidade em grandes eventos da área educacional, como no ENDIPE (Encontro Nacional de Didática e Prática de Ensino) e nas reuniões anuais da ANPED (Associação Nacional de Pós-Graduação e Pesquisa em Educação), as discussões giram predominantemente em termos de atuação dos profissionais, organização e políticas públicas para o Ensino Superior.

Pensamos, nessa perspectiva, que discutir a identidade dos formadores, investigar o que eles pensam de sua atuação é um importante ponto de pauta, quando se pretende refletir sobre os rumos e a qualidade da formação do profissional docente, principalmente a inicial. Nesse sentido, um dos "braços" de nossa pesquisa se insere no campo da produção de conhecimentos sobre os formadores de professores do Ensino Superior, especificamente professores que atuam em Cursos de Pedagogia de universidades públicas brasileiras.

Cabe salientar que a discussão ora apresentada é substrato de um estudo longitudinal, em andamento desde o ano de 2011, no âmbito do Grupo de Pesquisa: Profissão Docente, Formação, Identidade e Representações Sociais - GPDFIRS, da Faculdade de Ciências e Tecnologia - Campus UNESP de Presidente Prudente (FCT/UNESP), que adotou como objetivo geral identificar e analisar, de forma comparativa, o desenvolvimento da aprendizagem profissional da docência nos cursos oferecidos por distintas instituições públicas de ensino superior.

Assim, os dados ora apresentados foram coletados com o objetivo específico de compreender o pensamento de formadores de futuros professores sobre a aprendizagem da docência, no curso de Pedagogia, e são relativos a questões que compuseram questionário misto, utilizado no ano letivo de 2012.

\section{Formadores de professores: identidade em construção}

A docência ainda é um campo profissional abalado pelo entendimento do senso comum de que basta "saber bem" sobre algo (ser especialista) para poder ensinar bem... Este é um entendimento que interfere em todos os níveis de ensino, inclusive no Ensino Superior, pois muitos profissionais que nele atuam também a compreendem como uma verdade plausível. Mello (2012, p. 104) salienta:

A vivência na universidade nos permite observar que para muitos professores, para ensinar basta saber o conteúdo, sendo o exercício da docência, o verdadeiro lócus para se aprender a ensinar. Por não haver uma exigência legal de formação para a docência, como ocorre na educação básica, o entendimento sobre a docência neste nível de ensino parece que se tornou um não-lugar $e$, por vezes, cenário conflituoso. Muitos exercem sua função de formador, basicamente, a partir de concepções alternativas sobre ensino-aprendizagem desenvolvidas ao longo de sua trajetória, seja como estudantes ou como professores em situações eventuais, muitas das quais compartilhadas com outra profissão e quase sempre com maior status que a docência.

Sobre essa situação, Anastaciou (2006) aponta que, em grande parte dos casos, o professor universitário adormece profissional especialista de uma área e acorda professor. Como essa tem sido uma percepção frequente em relação ao professor, a necessidade de se investir nos saberes específicos para o seu exercício fica em segundo plano, persistindo a crença de que a experiência vivenciada é suficiente.

Para Behrens (2002, p. 60), muitos professores que atuam nas universidades brasileiras "[...] nunca exerceram as funções que apresentam aos seus alunos; falam de teoria sobre uma prática que nunca experienciaram".

Desse fato decorre que a categoria professor do ensino superior, de certa forma, ainda é pulverizada ou um campo (no sentido bourdieusiano da palavra) a ser construído, em grande medida também porque os docentes chegam ao ensino superior portadores de diferentes saberes, os quais lhes permitem refletir e propor novas e adequadas formas de ensinar; mas, por outro lado, grande parte 
adota os modelos cristalizados de ensinoaprendizagem com que estão familiarizados ou vivenciaram (MELLO, 2012).

Enfatiza Cunha (2006, p. 258):

$O$ ensino, especialmente o ensino de graduação, é entendido como decorrência das demais atividades, assumindo uma forma naturalizada de exercício. A naturalização da docência refere-se à manutenção dos processos de reprodução cultural como base da docência, ou seja, o professor ensina a partir da sua experiência como aluno, inspirado em seus antigos professores.

No caso dos professores que atuam em cursos de licenciatura, os formadores de professores, esta passa a ser uma situação ainda mais preocupante, pois não raramente eles demonstram ser totalmente leigos em profissionalização docente. São docentes que ensinam áreas científicas de uma dada especialidade e tendem a considerar o seu papel na formação inicial do professor também como específica, reservando o papel de discutir/formar para a docência aos colegas que se ocupam das disciplinas pedagógicas. Nas palavras de Rodrigues (2001, p. 2-3),

[...] uma parte significativa dos professores que leccionam didáctica de uma dada disciplina tendem também a ver-se como especialistas dessa disciplina, mais do que como formadores de professores do respectivo domínio científico. Por sua vez, reservam o papel de formador para os colegas da instituição de formação que se ocupam com a prática escolar e que coordenam os estágios realizados no ano terminal do curso pelos alunos-futurosprofessores.

Isso é reflexo da fragmentação da formação dos professores vivida nas licenciaturas, de forma geral, por onde passam os futuros professores e aqueles que virão a ser formadores de professores. Quer nos cursos de formação para atuação na Educação Básica, quer em todos os outros tipos de licenciatura específica, o ensino é organizado de modo fragmentado, sem a devida articulação entre as áreas disciplinares, sobretudo entre as disciplinas chamadas de específicas e as pedagógicas.

Lira e Sponchiado (2012, p. 12), alertam para o fato de que

[o] domínio de conteúdos não é o bastante para o exercício da docência em qualquer nivel. Os saberes e competências pedagógicas são elementos essenciais na capacitação própria e específica do professor, a ideia de que "aquele que sabe, sabe automaticamente ensinar" embora ainda defendida por alguns, está sendo superada pela razão das especificidades e complexidades do ato de ensinar e da aprendizagem (grifos no original).

No entanto, como nos lembra Gatti (2010, p. 1.358),

[...] historicamente, nos cursos formadores de professores esteve desde sempre colocada a separação formativa entre professor polivalente - educação infantil e primeiros anos do ensino fundamental - e professor especialista de disciplina, como também para estes ficou consagrado o seu confinamento e dependência aos bacharelados disciplinares.

Considerando essas características relativas à formação dos professores, os próprios formadores de professores, que são fruto de uma formação igualmente fragmentada, são os que têm a tarefa, em sua prática, de romper com esse modelo, próprio do paradigma da racionalidade técnica. O dilema está na questão já apontada de que formadores dos professores, porém, ainda estão em processo de constituição como grupo, com uma identidade profissional a ser construída. A problemática se acirra, pois, como já afirmou Mizukami (2005-2006), não há programas de formação para professores do ensino superior e apenas uma parte do corpo docente envolvido em cursos de formação de professores tem algum tipo de preparação pedagógica.

Mello (2012, p. 105) assinala:

A maioria dos professores titulados exerce as atividades docentes sem a necessária formação, incluindo àqueles que obtiveram a oportunidade de realizar o estágio de docência, exigido atualmente nos cursos de pós-graduação, sobretudo para os que recebem apoio financeiro em forma de bolsa de estudo.

Horizontes, v. 34, n. 1, p. 147-158, jan./jul. 2016 
Isso acontece porque, de acordo com Pimenta e Anastasiou (2002), no Brasil, não há uma regulamentação ou curso específico para a formação de docentes para o ensino superior, como acontece com outros níveis de ensino. Apesar de a LDB estabelecer, em seu artigo 66, que a "[...] preparação para o exercício do magistério superior far-se-á em nível de pós-graduação, prioritariamente em programas de mestrado e doutorado", é fato que a maioria dos professores que atua no ensino superior hoje é "preparada" em cursos de pós-graduação (mestrado e/ou doutorado), que reconhecidamente priorizam a formação para a pesquisa e a especialidade nos temas selecionados para estudo e investigação, em detrimento da formação para a docência.

Dessa maneira, a formação dos formadores de professores se realiza no modelo da autoformação, que Garcia (1999, p. 19) define como "[...] formação em que o indivíduo participa de forma independente e tendo sob seu próprio controlo os objetivos, os processos, os instrumentos e os resultados da própria formação". Importante salientar que os estágios de docência são extremamente importantes para a formação, no entanto, são bastante pontuais, uma vez que permitem a inserção do estudante na experiência de ensino em nível superior, mas muito raramente vêm acompanhados de uma disciplina ou discussão específica que possibilite a reflexão desencadeadora da profissionalização e da profissionalidade docente.

Arroyo (2004, p. 30) pondera que no conflito entre "[...] imagens sociais e imagens pretendidas pela categoria e auto-imagens pretendidas [...]" pelos docentes gera a dúvida sobre que profissionais eles são, qual sua identidade?

Nessa linha de pensamento, Cunha (2006, p. 259) alerta que:

Todos os professores foram alunos de outros professores e viveram as mediações de valores e práticas pedagógicas. Absorveram visões de mundo, concepções epistemológicas, posições políticas $e$ experiências didáticas. Os professores só alteram suas práticas quando são capazes de refletir sobre si e sobre sua formação.

Tal apontamento nos faz atribuir especial valor às imagens e auto-imagens que nos chama atenção Arroyo (2004), que são construídas social, cultural e politicamente, envoltas em muitos e diferentes interesses que extrapolam o universo escolar; o mesmo autor ainda salienta que por estas mesmas razões as imagens e auto-imagens da profissão docente não são unas.

Ainda acerca da identidade do docente universitário, Zabalza (2004) aponta, como outro problema, a identidade socioprofissional deste; segundo o autor, esta seria uma dimensão contraditória, pois se, por um lado, o título traz certo status social, por outro, essa dimensão fica num plano secundário em relação aos elementos envolvidos na construção e desenvolvimento desta identidade, porque, em muitos casos, os professores se definem (ou autodefinem) mais no âmbito científico de suas especialidades do que como docentes, de sorte que acabam se envolvendo mais com atividades voltadas para a área específica de sua formação (na escrita ou leitura de livros e artigos, participação em congressos, relações profissionais, pesquisas, etc.) do que com atividades docentes ou associadas à docência.

Assim, conforme ressalta Cunha (2006), as iniciativas visando a propiciar processos de desenvolvimento profissional, durante o desempenho das atividades profissionais, ficam na dependência de como cada instituição concebe a formação do formador e como tal formação está contemplada nos respectivos planos de desenvolvimento institucional.

Entretanto, conforme salienta Cunha (2006), em muitas áreas do conhecimento, os processos seletivos relacionados à contratação docente em instituições de Ensino Superior priorizam a linha de pesquisa e não a docência, as titulações, em detrimento das qualificações pedagógicas. É oportuno destacar que não estamos menosprezando o papel e o valor da pesquisa junto à prática docente (não só no ensino superior), pois cremos que a produção do conhecimento científico deve fazer parte do cotidiano igualmente como modo de incrementar a formação e ação docente. Compartilhamos a ideia freireana de que ensinar exige rigor, cuja tríade ensinar/aprender/pesquisar são elementos indissociáveis e uma das condições primordiais para a valorização da prática educativa (FREIRE, 1996).

Em conexão com essas considerações, encontramos em Snoeckx (2003, p. 30-31) apontamentos ligados à formação dos formadores de professores como "um saber construído sobre a experiência", em que faz indicações de que a formação pode efetuar-se no local de trabalho, onde os formadores são rapidamente integrados às ações de formação, devido às numerosas tarefas e às demandas da instituição cada vez mais prementes, com o número de pessoal sempre mais restrito e, 
nesse caso, a operacionalidade se torna necessária. $\mathrm{O}$ formador de professores, situado nesse contexto, torna-se um autodidata em potencial e em aceleração, afirmando ainda o autor que "[...] o formador em geral constrói suas competências na situação, elabora sua especialização sem que ela possa ser certificada e nem mesmo repertoriada".

No entanto, em meio a essa profusão de situações não muito satisfatórias e diferentes entendimentos a propósito da docência universitária, Mello (2002, p. 105) assinala que "[...] muitas instituições públicas brasileiras têm buscado soluções, utilizando como estratégia a obrigatoriedade [...], em relação à participação dos professores em cursos de formação", exigida comumente dos professores que iniciam a docência na instituição, porém, essa obrigatoriedade não inclui os que já estão em exercício.

Sendo considerada a necessidade de superar o processo de formação dos formadores de professores baseado exclusivamente na "autoformação", como "saber construído sobre a experiência" ou "autodidata em potencial", Mizukami (2005-2006) sugere quatro características fundamentais $^{3}$ necessárias aos formadores de professores as quais precisam ser contempladas em propostas de formação: 1- a importância de uma base de conhecimento sólida e flexível, fundamental para que o formador desempenhe suas funções, oportunizando situações e experiências que levem o futuro professor a "aprender a ensinar" de diferentes formas para diferentes tipos de sujeitos e contextos; 2- a pertinência e a necessidade de construção de estratégias de desenvolvimento profissional que não sejam invasivas e permitam objetivação de crenças, valores, teorias pessoais; 3- a importância da construção de comunidades de aprendizagem, nas escolas e nas universidades, as quais envolvam professores das escolas e formadores da universidade, de maneira a propiciar processos de desenvolvimento profissional mais apropriados à profissão docente; 4- a atitude investigativa como eixo da formação do formador, concebida como um processo contínuo e sistemático de investigação, no qual os participantes questionam suas suposições e as de seus pares e constroem conhecimento local e público adequado para contextos em mudança.

Ainda nessa perspectiva, Mizukami (20052006, não paginado) também propõe uma definição de formadores, chamando a atenção para o processo de formação dos formadores de professores, definindo-os como
[...] todos os profissionais envolvidos nos processos formativos de aprendizagem da docência de futuros professores ou daqueles que já estão desenvolvendo atividades docentes: os professores das disciplinas Prática de Ensino e Estágio Supervisionado, os das disciplinas pedagógicas em geral, os das disciplinas específicas de diferentes áreas de conhecimento e os profissionais das escolas que acolhem os futuros professores. Concebe-se aqui formação do formador como um processo continuado de autoformação - envolvendo dimensões individuais, coletivas e organizacionais desenvolvido em contextos e momentos diversificados e em diferentes comunidades de aprendizagem constituídas por outros formadores.

São estes alguns apontamentos e talvez focos necessários para se pensar processos formativos do formador, a serem levados em conta em políticas públicas educacionais, a partir de uma construção de conhecimentos para a atuação dos formadores de professores que contemplem processos coletivos, participativos, os quais valorizem o trabalho em equipe, rompendo assim com o processo único de autoformação e acrescentando processos formativos de interformação, que, como conceitua Garcia (1999, p. 20), é "“[...] a acção educativa que ocorre entre os futuros professores ou entre professores em fase de actualização de conhecimentos e que existe como um apoio privilegiado no trabalho da equipa pedagógica, tal como hoje é concebido para a formação do amanhã".

Assim, tendo em vista a natureza complexa e as muitas especificidades da docência no Ensino Superior, bem como a importância fundamental dos formadores em cursos de licenciatura, propomos a presente discussão, a qual gira em torno das imagens que os professores atuantes em cursos de Pedagogia têm sobre ser professor e, ainda, sobre ser professor que forma professores.

Nessa direção Arroyo (2004, p. 18), na discussão das imagens e auto-imagens dos profissionais da educação utiliza o termo "ofício de mestre" para caracterizar o saber-fazer dos professores, um fazer qualificado, profissional, “[...] que só eles sabem fazer, que lhes pertencem, porque aprenderam seus segredos, seus saberes e suas artes". $\mathrm{O}$ mesmo autor ainda aponta que existem muitas hierarquias no seio da profissão, havendo níveis e graus de imagens sociais bastante diferenciados, que 
dependem de variáveis tais como salário, carreira, titulação...; de acordo com Arroyo (2004, p. 30): "[c]ada grupo de docentes tem experiências peculiares do reconhecimento social"; no caso dos professores de educação infantil, estes carregam uma imagem pouco profissional, ou da não necessidade de formação profissional específica para o exercício de sua função, mas de características pessoais específicas como "gostar de crianças".

De maneira similar ocorre com o docente dos anos iniciais do Ensino Fundamental, cujo destaque é dado para a necessidade de ter,

[...] competência para o ensino das primeiras letras e contas, mas sobretudo carinho, o cuidado, a dedicação $e \quad o$ acompanhamento das crianças. [...] A imagem social ainda está marcada pelos traços de professora primária construídos por décadas. Ser professora ou professor é carregar uma imagem socialmente construída (ARROYO, 2004, p. 30).

Assim, neste trabalho, buscamos apreender as imagens que os professores do ensino superior têm sobre a profissão docente, em específico os profissionais que atuam em cursos de Pedagogia, que formam professores para atuar na educação infantil e primeiro ciclo do Ensino Fundamental.

Importante registrar que na discussão ora proposta não temos a intenção de trabalhar com conceitos de representação, embora nos interesse saber como os professores formadores se percebem profissionalmente.

\section{A pesquisa e seus apontamentos}

Conforme já anunciamos, a presente discussão é um recorte de uma pesquisa longitudinal, de abordagem qualitativa, em andamento desde o ano de 2011. O objetivo geral proposto na investigação é acompanhar estudantes matriculados em cursos de Pedagogia, ao longo de todo o processo de formação inicial para a docência, em distintas instituições públicas de ensino superior, bem como diagnosticar as condições de sua formação, com vistas à compreensão de como se dá a evolução da aprendizagem profissional. Os sujeitos são alunos e professores de dois cursos de Pedagogia, de duas regiões brasileiras distintas: uma do Sudeste (que será identificada como A) e outra do Centro-Oeste (a qual será identificada como B).

Cabe o esclarecimento que as duas universidades selecionadas para investigação são bastante representativas em suas regiões de origem; ambas estão entre as maiores e mais antigas instituições públicas de ensino superior que formam professores para educação básica no Brasil; os cursos por sua vez foram selecionados por serem lócus de trabalho de alguns membros do Grupo de Pesquisa que conduziu a investigação.

Em seu desenvolvimento, o estudo passou por quatro momentos de coleta de dados: o primeiro se deu no início do ano letivo de 2011, junto aos estudantes que haviam recém-ingressado no curso, os quais responderam a um questionário misto composto por 40 questões. Em 2012, segunda fase da pesquisa, um novo questionário foi utilizado, também misto, porém, respondido pelos formadores (professores que atuavam nos cursos de Pedagogia, na época); na terceira fase, ocorrida em 2013, os estudantes responderam a outro questionário misto, desta vez composto por 21 questões. Importante assinalar que a última coleta ocorreu no final do ano letivo de 2014, porém os dados ainda estão em processo de análise.

Assim, nos limites deste texto, cuja intenção é discutir a percepção que os professores formadores que atuam em cursos de formação inicial detêm sobre o que é ser professor e o que é ser formador de professores, serão apresentados dados referentes a duas questões abertas que compuseram o questionário respondido no ano de 2012, originalmente formuladas da seguinte forma: "Para você, ser professor hoje é...."; "Ser formador de professores é....".

Nesse sentido, trabalhamos com um universo de 33 sujeitos, constituído por 23 professores da Universidade A e 10 da Universidade B. Cabe destacar que, na análise dos dados, as respostas não foram consideradas excludentes e, por isso, chegamos a um total superior ao número de respondentes.

Todos os professores da Universidade A responderam à questão "Para você, ser professor hoje é...", sendo que vários atribuíram mais de uma resposta a ela, totalizando 36 respostas. De uma maneira geral, caracterizam o entendimento do professor como profissional capaz de provocar mudanças sociais, considerando que esta é uma tarefa complexa, sendo significativos sete apontamentos dessa complexidade e desafio, conforme exemplificado na sequência.

Ser professor hoje é assumir uma profissão complexa e essencial para a formação das 
pessoas no contexto histórico atual. [...] é necessário que o professor além da competência técnico-pedagógica esteja revestido de profundo compromisso político [...] (Sujeito 07_Univ. A).

É importante ter uma metodologia de trabalho que seja compatível com cada situação de sua disciplina, mais ainda, entender as especificidades de cada faixa etária em que atua. Não dispensar o trabalho com as ocorrências externas à escola e sua significação para a formação geral dos alunos. Acima de tudo conhecer muito bem os conteúdos com que deve trabalhar. Incentivar os múltiplos olhares sobre a área de conhecimento e suas intersecções com as demais [...] (Sujeito 16_Univ. A).

As considerações a respeito da complexidade da função do professor, em nossa análise, indicam um profissional que necessita pensar muitos aspectos na formação dos alunos, objetivando uma formação integral.

Em seguida, temos seis respostas que evidenciam que ser professor hoje é provocar mudanças, construir uma sociedade mais justa, ter compromisso político. Essas ideias revelam o quanto é importante ter compromisso com a profissão, realçando uma prática cidadã, principalmente quando se referem à construção de uma sociedade mais justa, que contemple justiça social. Também com seis respostas, temos a indicação de formar pessoas para a participação social, sublinhando novamente uma prática cidadã, uma militância, uma vez que põe uma importância grande na participação social, a qual pode ter um caráter tanto assistencial como político.

Ser formador de pessoas para o cuidado de si e do outro, para participar na vida pública e construção de uma sociedade mais justa e democrática (Sujeito 06_Univ. A).

Perceber-se agente de transformação. Ter consciência de um mundo em mudanças, de gerações que se formam influenciadas por muitas mídias, mas que o papel da escola é o de organizador desse universo, juntandose ao universo familiar. É fundamental ensinar a lidar com as diferenças e discutilas [...] (Sujeito 16_Univ. A).
Igualmente significativas e relativas ao domínio dos conteúdos, das metodologias, de saber ensinar, temos cinco respostas que abordam tais questões, demonstrando que é necessário, para ser professor, ter conhecimento dos conteúdos a serem ensinados e saber como ensinar, o que enfatiza uma concepção laboral do ser professor, pela característica do ser possuidor do saber técnico.

Ter formação científica. Ter capacidade de ensinar de forma que o aluno aprenda. Ser capaz de verificar dificuldades e elaborar estratégias para superação dos problemas. Saber atuar com estratégias para superação dos problemas. Saber atuar com sabedoria na transmissão de valores, ou seja, saber ouvir o aluno, dialogar, orientar em diferentes sugestões/aspectos da vida [...] (Sujeito 15_Univ. A).

Ter domínio de conteúdos para ensinar de modo significativo aos alunos em formação, ter conhecimento do currículo, dos alunos e da instituição, das políticas que orientam a formação (Sujeito 11_Univ. A).

Ainda surgem, com menor frequência, as ideias: grande responsabilidade, realização, ser gratificante, saber administrar relações interpessoais, gostar de ensinar e gostar de aprender; além disso, com apenas uma indicação cada uma, compreender as demandas da escola pública e criar saberes. Apenas um sujeito não respondeu de modo que possibilitasse considerar a resposta.

No que diz respeito à Universidade $\mathrm{B}$, os 10 professores responderam à questão, mas somente um teve sua resposta enquadrada em mais de uma categoria, totalizando 11 respostas.

Nesse grupo, destacam-se as ideias de preparar sujeitos sociais e mudar a sociedade, com três indicações, remetendo a uma concepção militante; três respostas frisam um desafio e tarefa desgastante, enquanto outras três aludem a identificar-se com o que se faz, ter paixão pelo que se faz, evidenciando tanto compromisso quanto uma concepção romântica do ser professor.

[...] ter como mote a mudança da sociedade através do processo da ensinagem (levar o outro a aprender) (Sujeito 01_Univ. B).

[...] ter paixão pelo conhecimento e pela humanidade (Sujeito 03_Univ. B). 
[...] assumir intensamente seu processo de formação inicial e continuada como ferramenta ideológica/profissional na (re) construção do espaço escolar e da compreensão da educação no mundo contemporâneo (Sujeito 09_Univ. B).

Com menor frequência, temos as respostas sobre ser professor vinculado a ser ético, com uma indicação, que está associado ao estatuto da profissão, ao passo que uma das respostas direciona para as questões laborais específicas da universidade, que é a articulação pesquisa/ensino e extensão.

Podemos concluir, nessa primeira questão, que as duas universidades têm professores com concepções semelhantes sobre o "ser professor hoje", pois aparecem, em ambas, as indicações relativas à construção de uma sociedade mais justa, a necessidade de uma prática que provoque mudanças, com ênfase na participação social, revelando a preocupação com práticas as quais direcionem para uma formação cidadã, militante, engajada com as questões sociais.

No que concerne à questão "Ser formador de professores é...", obtivemos 37 respostas dos professores da universidade A e 10 da universidade B. De modo geral, as respostas, tanto dos profissionais da universidade A quanto da universidade $\mathrm{B}$, reforçam as respostas dadas à questão anterior, alternando-se apenas a frequência.

As respostas dos sujeitos da universidade $\mathrm{A}$ assinalam essa questão, com seis indicações, enfatizando a preocupação com as mudanças sociais e da escola, mais relacionadas, nesse caso, a se estar concatenado com as transformações da sociedade e que resultam em mudanças na escola. Com a mesma frequência (seis), temos a formação de pessoas para a participação e a necessidade de conscientização, também ressaltando a necessidade de um engajamento social.

Em seguida, com quatro indicações, temos o gostar de estudar e atualizar-se constantemente, revelando o compromisso com a formação continuada como condição para ser formador de professores; também com quatro respostas, temos o domínio de conteúdos, didáticas e metodologias, igualmente ocorrente na questão anterior.

Ter interesse pela escola, participação nas mudanças que a escola e a sociedade precisam, saber fazer o aluno gostar da disciplina, e, sobretudo gostar de estudar. Saber profundamente os conteúdos que ensina, incluindo os pedagógicos, e pesquisa (Sujeito 05_Univ. A).

Ter compromisso com o que se faz em diferentes aspectos. Tanto na transmissão de conteúdos, quanto no ensino de práticas, quanto no desenvolvimento de diálogo crítico que leva à conscientização sempre considerando a realidade de sala de aula para onde se supõe que os alunos irão escola pública (Sujeito 15_Univ. A).

Com menor frequência, temos "ter responsabilidade, compromisso", "algo que gosto, gratificante", "desconstruir a visão idealizada da profissão e da escola", "convencer-se da responsabilidade da profissão", "tarefa complexa, um desafio", "ensinar e aprender", e, por fim, "tarefa que exige trabalho coletivo", com apenas uma indicação, sendo o único sujeito que sublinhou uma visão que contempla a interformação na tarefa de ser formador de professores.

Sobre as respostas dos formadores da universidade B, com quatro indicações, temos "ser responsável por formar sujeitos sociais, por construir uma sociedade melhor, provocar mudanças", reafirmando o caráter da prática cidadã, da formação para a cidadania, sendo esta a resposta de maior frequência. Em seguida, com duas ocorrências, temos "um desafio", também presente na questão anterior; em acréscimo, com apenas uma indicação cada uma, "gostar do que faz"; "grande responsabilidade"; "ser ético"; "ter compromisso".

[...] uma grande responsabilidade (Sujeito 07_Univ. B).

[...] romper as visões estereotipadas e cristalizadas que o aluno (futuro professor) chega no curso [...] (Sujeito 08_Univ. B).

[...] tencionar o estudante em formação a todo momento a se embrenhar em novas aventuras interpretativas e novas descobertas [...] é vislumbrar transformação [...] (Sujeito 09_Univ. B).

Como podemos observar, as respostas à questão sobre ser formador de professores repetem ou reafirmam as respostas à pergunta sobre ser professor hoje, sendo as respostas oferecidas pelos professores das duas universidades bastante 
semelhantes; apenas as indicações relativas ao domínio dos conteúdos e metodologias, as quais aparecem como uma das marcas das respostas dos formadores da Universidade A, inexistem na Universidade B.

\section{Breves considerações}

[...] o intelectual não cria o mundo no qual vive. Ele já faz muito quando consegue ajudar a compreendê-lo e explicá-lo, como ponto de partida para sua alteração real (FERNANDES, 1980, p. 241).

A expansão de vagas na educação básica, conforme se destacou na introdução, carrega em seu bojo a discussão sobre qualidade aliada à igualdade de oportunidades em educação. No entanto, no contexto brasileiro, a preocupação com a qualidade tornou-se "pauta" somente após essa expansão, porque primeiramente se procurava universalizar o acesso à educação, sem grandes preocupações com os sujeitos responsáveis por esse processo - os professores - e também os formadores desses professores.

Entretanto, é importante considerar que a democratização do ensino só se concretiza se traz consigo a valorização dos profissionais atuantes na escola - neste caso, os professores. Isso nos remete à questão: como assegurar quantidade e qualidade na escola básica, se há tempos nos debatemos com os limites da formação inicial de professores para esse nível de ensino?

Nos últimos tempos, é consenso entre todos os envolvidos diretamente (e indiretamente) com educação a meta do ensino de qualidade. Mas, para assegurar que essa qualidade seja "positiva", é necessário um olhar mais cuidadoso para o professor e sua formação, pois ele tem um papel fundamental em qualquer projeto de mudança social, pois, como bem nos lembra a tese freireana, qualquer que seja a mudança desejada, sua figura será sempre central.

Nesse sentido, se pensarmos na garantia da qualidade da educação, é imprescindível dirigir a atenção aos formadores dos professores, uma vez que são eles que atuam na formação em nível superior. Cabe reforçar o apontamento de que a formação dos formadores é uma questão a qual tem começado a despertar o interesse dos pesquisadores, porém, esta ainda não é realizada de forma contundente e tampouco abarca todas as questões necessárias para que haja significativo avanço. Mello (2012, p. 119) sinaliza que:
A educação superior no Brasil nas últimas décadas tem se consolidado em um modelo de diversificação, internacionalização, centrado na lógica expansionista, com aumento expressivo no número de instituições, cursos de graduação e de alunos. Com o foco constante $d a$ democratização do acesso, cresce também o número de profissionais contratados para o exercício da docência em instituições de ensino superior. Por isso, a discussão sobre a docência universitária tornou-se assunto de relevância no contexto da pesquisa educacional.

Tais questões nos põem em alerta ainda pelo fato de estar em amplo crescimento, principalmente, o número de cursos de licenciatura no país, o que demanda a urgência de elaboração de propostas mais adequadas para a formação dos formadores e o desafio de refletir sobre o ensino superior, porque, no cotidiano das salas de aula do ensino superior, é possível observar que o professor universitário estabelece, a partir de suas vivências e imagens da docência, uma relação com o conhecimento e os aprendizes de um modo secularmente superado.

Isso se torna mais preocupante, quando percebemos o anacronismo de nossas práticas pedagógicas e de nossas escolas. O professor José Pacheco, reconhecido internacionalmente por sua experiência na Escola da Ponte, em Portugal, nos adverte com o seguinte comentário:

Falar do papel do professor é falar sobre o papel da escola dentro da sociedade. E a escola que nós temos, que nos habituamos, é tributária das necessidades do século 19. Não tem nada a ver com a sociedade do século 21. O problema é que temos escolas do século 19... Com todo o respeito que tenho pelos professores que sofrem nas escolas. O papel do professor é múltiplo no século 21. O problema é que temos alunos do século 21, com professores do século 20 a trabalhar como no século 19 [...] (PACHECO, 2013, p. 24).

Canário (2008, p. 79), por sua vez, já afirmava que "[...] a escola na configuração histórica que conhecemos (baseada num saber cumulativo e revelado) é obsoleta, padece de um défice de sentido para os que nela trabalham (professores e alunos) [...]", sendo de igual maneira marcada pela crescente 
perda de legitimidade social, pois não tem cumprido seu papel precípuo de socializar os conhecimentos e diminuir as desigualdades.

Tais alertas, sem dúvida, nos levam a refletir sobre a urgente necessidade de ressignificar $\mathrm{e}$ redimensionar os projetos de formação de professores, considerando especialmente o papel a ser desempenhado pelo professor formador de professores.

Mello (2012) esclarece que já há muitas experiências de formação de formadores em instituições de ensino brasileiras, como a UFG, UFPE e UNICAMP, "[...] algumas com estruturas robustas" (MELLO, 2012, p. 106). Todavia, infelizmente, estas ainda são iniciativas pontuais.

Em rápida pesquisa junto ao site do Instituto Nacional de Estudos e Pesquisas "Anísio Teixeira" (INEP) ${ }^{1}$, verificamos que, em 2011, o Brasil contava com 7.911 cursos de licenciatura, sendo 4.065 $(51,4 \%)$ desses cursos localizados em instituições públicas e $3.846(48,6 \%)$ em instituições privadas. Os dados mostram ainda que existem 1.801 cursos de Pedagogia (espaço por excelência de formação do professor para atuação na educação básica), sendo $611(33,9 \%)$ deles oferecidos em instituições públicas e $1.190(66,1 \%)$ em instituições privadas. Foi possível observar, em acréscimo, que a expansão do ensino superior tem atingido, em especial, os cursos de formação de professores. Tal contexto enseja e justifica o crescente interesse pelos espaços de formação e, principalmente, pelos sujeitos formadores.

A realização da pesquisa ora relatada nos faz inferir que o processo de formação dos formadores de professores realmente continua sendo de autoformação e de um saber construído sobre a experiência, na situação de autodidatismo em potencial e em aceleração. Os dados sobre o que é ser formador de professores corroboram esse entendimento, sobretudo quando os formadores apontam questões como a preocupação com as mudanças sociais de forma genérica, em detrimento de questões mais pontuais acerca de suas tarefas.

A propósito da percepção que os formadores têm sobre a profissão docente, cabe destacar que os docentes da Universidade A assinalaram, com uma frequência expressiva, a questão relativa a ser uma tarefa complexa, um desafio, atribuindo-lhe, de certa forma, uma concepção missionária, a qual decorre de uma visão apostólica do ensino, também expressiva nos professores da Universidade B.

Acreditamos que a tão propalada atitude reflexiva necessária ao profissional docente envolve o desenvolvimento de algumas características, tais como: não se ver como detentor de um saber acabado, permitindo-se aprender constantemente; compreender que as práticas são construídas em conjunto; saber lidar com as dúvidas e incertezas como parte do processo de aprendizagem e a compartilhar os saberes e fazeres da prática pedagógica.

As respostas oferecidas pelos formadores despertam certa dúvida se elas denotam totalmente essa compreensão... Nenhum sujeito faz menção à necessidade de realizar o trabalho de formação de maneira coletiva e de despertar a consciência deste fato em seus aprendizes; o destaque é feito para a compreensão do papel transformador da profissão, mas não para o entendimento de que esta é uma tarefa que necessita ser assumida pelo grupo de profissionais para que possa ter resultados mais amplos e efetivos; que esta função, diferentemente da pesquisa, por exemplo, é essencialmente coletiva.

Tal fato nos impele a reafirmar a ideia de Lira e Sponchiado (2012, p. 13), a respeito da importância de encarar a docência universitária

[...] como uma prática complexa que requer leituras culturais, políticas e pedagógicas a respeito dos objetos de ensino, dos contextos e dos sujeitos envolvidos. Ao contrário do que comumente se pensa no ambiente acadêmico, a ação de ensinar é portadora de desafios e requer respostas possivelmente mais complexas do que o universo da pesquisa; ensinar como estudar, como aprender, como questionar, como organizarse são também atribuições do trabalho docente.

Tais tarefas adquirem, por conseguinte, um sentido diferenciado, quando se coloca em questão que estão em processo de formação de novos (ou futuros) professores. Cabe, desse modo, apontar que a formação de profissionais docentes com qualidade positiva não é tarefa simples, pois requer aprofundamento científico e pedagógico que lhes possibilite construir a capacidade de enfrentar as questões e adversidades cotidianas do "universo escola" e refletir constantemente, durante o seu exercício pedagógico.

O senso comum (e não só ele) afirma que "ensinar é uma arte" - e isso é fato; mas é preciso construir o entendimento de que esta é uma arte que se constrói em diferentes instâncias; uma arte que precisa ser aperfeiçoada, dia a dia, através de 
posturas críticas, de reflexões constantes, da construção de uma práxis que permita o desenvolvimento e a transformação de sujeitos e contextos...

\section{Notas}

1 Disponível em: http://portal.inep.gov.br/superiorcensosuperior-sinopse. Acesso em 07 out. 2014.

2 Florestan Fernandes (1975), citado por FRIGOTTO, G. A polissemia da categoria trabalho e a batalha das ideias nas sociedades de classe. Revista Brasileira de Educação, v. 14, n. 40, p. 168-194, jan./abr. 2009.

3 Segundo a própria autora, esta proposta é baseada na ideia trazida por COCHRAN-SMITH, M. Learning and unlearning: the education of teatcher educators. Teaching and teacher Education, 19, p. 5-28, 2003.

4 FERNANDES, F. A sociologia no Brasil. Petrópolis: Vozes, 1980.

\section{Referências}

ANASTACIOU, L. G. C. A docência no ensino superior: desafios e possibilidades. Forgrad em Revista - ensino de Graduação: desafios e perspectivas teóricas, Vitória, v. 1, p. 5-8, maio/2006.

ARROYO, M. G. Ofício de mestre: imagens e autoimagens. 7. ed. Petrópolis: Vozes, 2004.

BEHRENS, M. A. A formação pedagógica e os desafios do mundo moderno. In: MASETTO, M. (Org.). Docência na universidade. 4. ed. Campinas: Papirus. 2002. p. 57-68.

BRASIL. Lei n. 11.114/2005. Brasília. Disponível em: www.planalto.gov.br. Acesso em: 13 nov. 2010.

Lei n. 11.274/2006. Brasília. Disponível em: www.planalto.gov.br. Acesso em: 13 nov. 2010.

Conselho Nacional de Educação. Resolução $\overline{C N E / C P}$ 01, de 18 de fevereiro de 2002. Institui Diretrizes Curriculares Nacionais para a Formação de Professores da Educação Básica, em nível superior, curso de licenciatura, de graduação plena, 2002. Disponível em: http://portal.mec.gov.br/cne/arquivos/pdf/CP012002 .pdf. Acesso em: 03 mar. 2013.

Conselho Nacional de Educação. Parecer CNE/CP 09, de 08 de maio de 2001. Diretrizes Curriculares Nacionais para a Formação de Professores da Educação Básica, em nível superior, curso de licenciatura, de graduação plena. Brasília. Disponível em: $\langle$ http://portal.mec.gov.br/cne/arquivos/pdf/009.pdf $>$ . Acesso em: 02 mar. 2013.

Conselho Nacional de educação. Resolução $\overline{C N E / C P} n^{\circ} 01$, de 15 de maio de 2006. Institui Diretrizes Curriculares Nacionais para o Curso de Graduação em Pedagogia, licenciatura, 2006. Disponível em: <http://portal.mec.gov.br/cne/arquivos/pdf/rcp01 0 6.pdf>. Acesso em: 03 mar. 2013.

Lei $N^{\circ}$ 9.394, de 20 de dezembro de 1996. Estabelece as Diretrizes e Bases da Educação Brasileira. Disponível em: http://www.planalto.gov.br/ccivil_03/Leis/L9394.ht m. Acesso em: 02 mar. 2013.

CANÁRIO, R. A escola: das "promessas" às “incertezas". Educação Unisinos, São Leopoldo, v. 12, n. 2, p. 73-88, maio/ago., 2008.

CUNHA, M. I. Docência na universidade, cultura e avaliação institucional. Revista Brasileira de Educação, v. 11 n. 32, p. 258-371, maio/ago. 2006. Disponível em: http://www.scielo.br/pdf/rbedu/v11n32/a05v11n32. pdf. Acesso em: 18 maio 2014.

FREIRE, P. Pedagogia da autonomia: saberes necessários a prática educativa. São Paulo: Paz e Terra, 1996.

GARCIA, C. M. Formação de professores - para uma mudança educativa. Porto: Porto Editora, 1999.

GATTI, B. A. Formação de professores no Brasil: características e problemas. Revista Educação e Sociedade, Campinas, v. 31, n. 113, p. 1355-1379, out./dez., $2010 . \quad$ Disponível em: http://www.cedes.unicamp.br. Acesso em: 01 maio 2014.

LIRA, D.; SPONCHIADO, D. A. M. A formação pedagógica do profissional docente do ensino superior: desafios e possibilidades. Perspectiva, 
Erechim, v. 36, n. 136, p. 7-15, dez. 2012.

MELLO, I. C. A docência no ensino superior: descrição e análise de um percurso formativo. In: KASSAR, M. de C. M.; SILVA, F. de C. T. (Org.). Educação e pesquisa no Centro-Oeste: políticas, práticas e fontes da/para a formação do educador. Campo Grande: UFMS, 2012. p. 103-121.

MIZUKAMI, M. G. N. Aprendizagem da docência: professores formadores. Revista E-Curriculum, São Paulo, v. 1, n. 1, dez.-jul. 2005-2006. Disponível em: http://www.pucsp.br/ecurriculum. Acesso em: 01 maio 2014.

PACHECO, J. Projeto em Cotia refaz papéis da escola e do professor. Revista Caros Amigos, São Paulo, v. 64, p. 24. Disponível em: http://lojacarosamigos.com.br/Produto-EdicoesTematicas-2013-Ed-064-Os-Desafios-da-Educacao- versao-1230-1227.aspx. Acesso em: 24 out. 2014.

PIMENTA, S. G.; ANASTASIOU, L. G. C. Docência no Ensino Superior. São Paulo: Cortez, 2002.

RODRIGUES, Â. A formação de formadores para a prática na formação inicial de professores, 2001. Disponível em: http://www.educ.fc.ul.pt. Acesso em: 01 maio 2014.

SNOECKX, M. Formadores de professores, uma identidade ainda balbuciante. In: ALTET, M.; PAQUAY, L.; PERRENOUD, P. (Org.). A profissionalização dos formadores de professores. Porto Alegre: Artmed, 2003.

ZABALZA, A. O ensino universitário: seu cenário e seus protagonistas. Porto Alegre: Artmed, 2004.

\section{Sobre os autores}

Sílvia Adriana Rodrigues é graduada em Pedagogia, Mestre em Educação pela FCT/UNESP e Doutoranda na mesma instituição. Professora Assistente da Universidade Federal do Mato Grosso do Sul - Campus de Corumbá. Membro do Grupo de Pesquisa Profissão Docente, Formação, Identidade e Representações Sociais - GPDFIRS da FCT/UNESP. Líder do Grupo de e Estudos Pesquisas sobre Infâncias e Educação Infantil - GEPIEI da UFMS/CPAN.

Simone Conceição Pereira Deák é graduada em Geografia e Pedagogia. Doutora em Educação pela FCT/UNESP. Coordenadora Pedagógica da Secretaria Municipal de Educação de Presidente Prudente. Professora da UNIESP Campus de Presidente Prudente. Membro do Grupo de Pesquisa Profissão Docente, Formação, Identidade e Representações Sociais - GPDFIRS da FCT/UNESP.

Alberto Albuquerque Gomes é graduado em Ciências Sociais, Doutor em Educação pela UNESP e com estágio de pós-doutoramento em Sociologia da Educação na Universidade Lusófona de Humanidades e Tecnologia em Lisboa-Portugal. Líder do Grupo de Pesquisa Profissão Docente, Formação, Identidade e Representações Sociais - GPDFIRS da FCT/UNESP.

Recebido em outubro de 2014. Aprovado em fevereiro de 2016. 